\title{
Locally advanced anal small cell carcinoma with durable complete response to chemoradiation followed by consolidation chemotherapy: case report and literature review
}

\author{
Jeremy Chuang ${ }^{1}$, Chongkai Wang ${ }^{1}$, Vishwas Parekh ${ }^{2}$, Marwan Fakih ${ }^{1}$ \\ ${ }^{1}$ Department of Medical Oncology and Therapeutics Research, City of Hope Comprehensive Cancer Center, Duarte, CA, USA; ${ }^{2}$ Department of \\ Pathology, City of Hope National Medical Center, Duarte, CA, USA \\ Correspondence to: Marwan Fakih, MD. Professor, Department of Medical Oncology and Therapeutics Research, City of Hope Comprehensive \\ Cancer Center, 1500 E. Duarte Road, Duarte, CA 91010, USA. Email: mfakih@coh.org.
}

\begin{abstract}
Extrapulmonary small cell carcinoma (EPSCC) is a rare and aggressive clinical entity that can involve a variety of anatomic locations, including the gastrointestinal tract. Involvement of the gastrointestinal tract is associated with a particularly poor prognosis with patients often presenting with widespread dissemination on initial clinical presentation or rapidly progressing to systemic disease from locoregional involvement. Primary small cell carcinoma of the anal canal is extremely rare, with limited published case reports in the literature. As a result, management of this disease is not well defined, and outcomes are poor with high rates of disease relapse. We report a patient with locally advanced anal small cell carcinoma after presenting with irregular bowel movements, changes in stool caliber, and rectal bleeding for two months and achieved a durable complete response to concurrent chemoradiation with cisplatin and etoposide followed by consolidation chemotherapy and discuss our current understanding of this disease. Specifically, we review the epidemiology, risk factors, clinical course, the treatment strategies over the past two decades, and prognosis for EPSCC. Finally, we conclude our discussion by reviewing the rationale of our treatment regimen and the potential role and benefit of consolidation therapy in the management of this rare and aggressive disease.
\end{abstract}

Keywords: Small cell carcinoma; anal cancer; extrapulmonary small cell carcinoma (EPSCC); gastrointestinal malignancy; case report

Submitted Jul 21, 2021. Accepted for publication Sep 29, 2021.

doi: 10.21037/jgo-21-434

View this article at: https://dx.doi.org/10.21037/jgo-21-434

\section{Introduction}

Anal cancer is an uncommon malignancy of which the majority are squamous cell cancers that have wellestablished treatments and overall favorable prognosis (1). However, primary small cell carcinoma of the anus is an extremely rare and aggressive clinical entity with poorly defined treatment and unfavorable prognosis. In this case report and literature review, we report a patient with locally advanced small cell carcinoma of the anus with a durable complete response after treatment with concurrent cisplatin and etoposide with radiation therapy followed by four cycles of consolidation chemotherapy with cisplatin and etoposide. Given the overall favorable and durable response to treatment with chemoradiation and consolidation chemotherapy, this treatment strategy may represent a new paradigm for the management of this rare and poorly understood disease. We present the following case in accordance with the CARE reporting checklist (available at https://dx.doi.org/10.21037/jgo-21-434).

\section{Case presentation}

A 66-year-old female with no significant past medical or family history initially presented with irregular bowel movements, changes in stool caliber, and rectal bleeding for 
Table 1 Timeline of significant clinical care events

\begin{tabular}{|c|c|}
\hline Significant clinical events & Dates \\
\hline Chemoradiation with cisplatin and etoposide & $9 / 17 / 2018-10 / 22 / 2018$ \\
\hline Cycle 1 of consolidation chemotherapy with cisplatin and etoposide & $11 / 23 / 2018-11 / 25 / 2018$ \\
\hline Cycle 2 of consolidation chemotherapy with cisplatin and etoposide & $12 / 14 / 2018-12 / 16 / 2018$ \\
\hline Cycle 4 of consolidation chemotherapy with cisplatin and etoposide & $1 / 25 / 2019-1 / 27 / 2019$ \\
\hline Surveillance & 2/15/2019-present. Last follow-up date on 3/17/2021 \\
\hline
\end{tabular}


Figure 1 Anal small cell carcinoma histopathology. (A) H\&E stain shows clusters of small round blue cells with nuclear molding, high nuclear:cytoplasmic ratio, evenly distributed chromatin without nucleoli, frequent apoptosis and mitosis, and focal crush artifact. (B) Pancytokeratin shows patchy cytoplasmic and dot-like positivity. (C) Synaptophysin shows rare focal cytoplasmic positivity. (D) Ki-67 demonstrates very high proliferative rate. (Original magnification $400 \times$ for all stains) (COLOR in-print).

two months prior to presentation (Table 1). Initial physical exam demonstrated a large, indurated mass in the anus encompassing the anal sphincter muscle. A colonoscopy was subsequently performed, which identified a partially obstructing, friable, partially circumferential mass starting at the dentate line and extending into the mid rectum. A biopsy of the mass demonstrated histomorphologic and immunophenotypic features consistent with small cell neuroendocrine carcinoma (Figure 1).

Initial laboratory studies were largely unremarkable except a normocytic anemia with hemoglobin of $10.5 \mathrm{~g} / \mathrm{dL}$. Staging computerized tomography (CT) studies of the chest, abdomen, and pelvis demonstrated a $6 \times 4 \times 8 \mathrm{~cm}^{3}$ mass in the anus with associated multiple enlarged left inguinal lymph nodes. A subsequent MRI of the abdomen and pelvis along with 18 F-FDG PET scan confirmed a large $12.7 \times 7.9 \times 5.9 \mathrm{~cm}^{3}$ mass in the anus associated with an enlarged $1.3 \mathrm{~cm}$ perirectal lymph node; no distant metastases were identified (Figure 2).

The patient was treated with definitive concurrent chemoradiation with cisplatin $50 \mathrm{mg} / \mathrm{m}^{2}$ on days 1,8 , 29,36 and etoposide $50 \mathrm{mg} / \mathrm{m}^{2}$ on days $1-5$ and $29-33$. She received a total dose of 59 Gy in 32 fractions (45 Gy in 1.8 per fraction followed by boost RT to gross tumor 

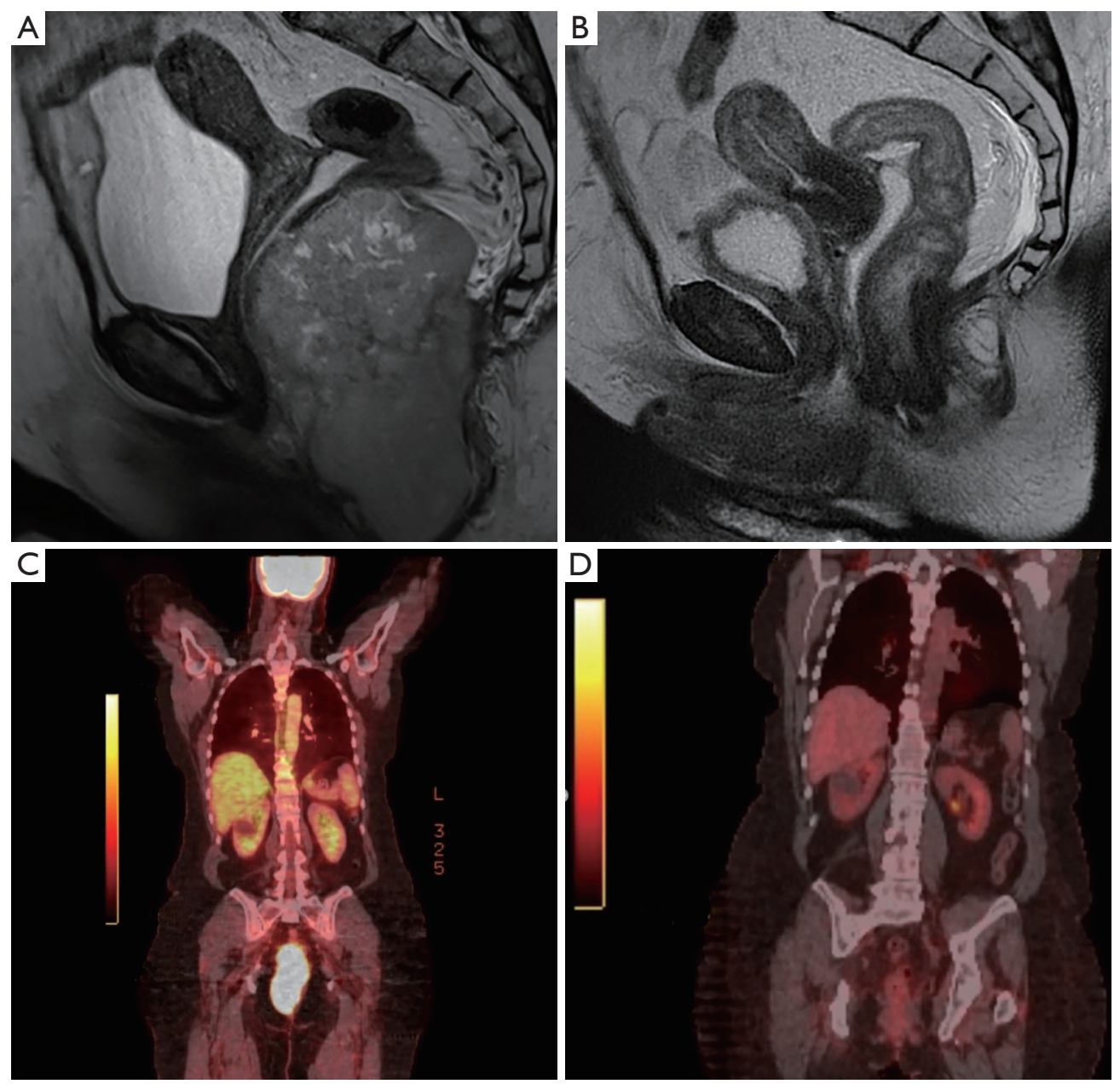

Figure 2 PET/CT radiographic images. (A) Pre-treatment sagittal T2 MRI demonstrating $12.7 \times 7.9 \times 5.9 \mathrm{~cm}^{3}$ mass anal mass extending in the rectum. (B) Post-treatment sagittal T2 MRI demonstrating complete resolution of anal mass. (C) Pre-treatment coronal 18F-FDG PET fused images demonstrating FDG-avidity of anal mass with a SUV 24.2 (COLOR in-print). (D) Post-treatment coronal 18F-FDG PET fused images demonstrating resolution of anal mass after completion of treatment (COLOR in-print).

at the anal canal for 14 Gy in 2 Gy per fraction) using helical tomotherapy to cover the anorectal canal and the regional lymph nodes, including mesorectum, bilateral inguinal, external and internal iliac, and common iliac lymph nodes. Within a few weeks of starting treatment, the patient developed marked improvement in pain and bowel movement frequency. No significant adverse reactions or unanticipated events from therapy were reported. Two weeks after completion of therapy CT scans of the chest and MRI of the abdomen and pelvis demonstrated a significant response to treatment with a decrease in size of mass to $1.2 \times 0.8 \times 1.1 \mathrm{~cm}^{3}$ from $12.7 \times 7.9 \times 5.9 \mathrm{~cm}^{3}$. MRI of the brain did not show evidence of brain metastases.

Given concern for high risk of relapse, the patient was treated with an additional four cycles of consolidation chemotherapy with cisplatin $75 \mathrm{mg} / \mathrm{m}^{2}$ on day 1 and etoposide $100 \mathrm{mg} / \mathrm{m}^{2}$ on days $1-3$ every 21 days four weeks after completion of chemoradiation. Six weeks after completion of treatment, clinical examination and flexible sigmoidoscopy demonstrated complete regression of the anal tumor. Repeat imaging with CT of the chest and MRI of the abdomen and pelvis along with 18F-FDG PET confirmed a complete response to therapy. Nearly 36 months from initial diagnosis, the patient continues to have no clinical or radiographic evidence of disease recurrence and remains on close surveillance which entails a history and physical examination including a rectal exam with PET/CT imaging every 6 months. 
All procedures performed in studies involving human participants were in accordance with the ethical standards of the City of Hope institutional review board and with the Helsinki Declaration (as revised in 2013). This study was conducted under an Institutional Review Board approved protocol (IRB14361). Because this was an outcome analysis study and the case was de-identified, the Institutional Review Board did not require an informed consent.

\section{Methods}

We discuss a rare case of anal small cell carcinoma which initially presented with irregular bowel movements, changes in stool caliber, and rectal bleeding along with its management and treatment outcomes. We also performed a literature search using MEDLINE to identify clinical studies (including case reports or series and any observation, retrospective studies) that discussed cases of patients with anal small cell carcinoma along with their management and overall outcomes to treatment. The search was limited by the following key words: anal small cell carcinoma, extrapulmonary small cell carcinoma (EPSCC), and treatment outcomes. A manual search was also performed to include additional studies of potential relevance.

\section{Discussion}

Small cell carcinoma is a high-grade poorly differentiated malignancy with neuroendocrine differentiation. It is an aggressive clinical entity that commonly arises in the lungs. However, extrapulmonary small cell carcinoma (EPSCC) is well-recognized and known to frequently occur in the genitourinary, gynecologic, and gastrointestinal tract $(2,3)$. Each year approximately 1,000 new cases of EPSCC are diagnosed, representing $0.1 \%$ to $0.4 \%$ of all cancers diagnosed in the United States and 2.5 to $5 \%$ of all small cell carcinoma Prognosis for EPSCC is poor with a median overall survival (OS) of 1.2 years with recent data suggesting that anatomic location influences clinical outcomes. EPSCC involving the gastrointestinal is associated with the worse prognosis while EPSCC involving the head and neck, and breast have improved overall survival (3-5). The impact of anatomic location on outcomes is postulated to be related to the effect on the timing of the initial presentation.

Of the cases involving the gastrointestinal tract, the majority of reported cases involve the esophagus, colon, and rectum (6). Small cell carcinoma of the anal tract is extremely rare, and the true incidence of this entity is not known. The predominant discussion of this disease in the literature has been largely limited to a handful of case reports (Table 2) (7-15). The majority of the patients were treated with a multimodality approach consisting of chemotherapy with cisplatin and etoposide along with radiation therapy. Surgery was commonly used as salvage therapy for local recurrence. Many patients had rapid disease progression and nearly all patients had an overall survival of less than 12 months after diagnosis. While there is a strong association between select high-risk subtypes of human papillomavirus (HPV) and HIV with the development of squamous cell carcinoma of the anus, the risk factors for the development of anal small cell carcinoma are not well established. However, several cases of anal small cell carcinoma have been reported to develop in patients with both HIV and HPV $(7,9,13,16)$.

Small cell carcinoma of the gastrointestinal tract commonly presents with widespread dissemination (3). Even patients who initially present with locoregional involvement progress rapidly to systemic disease (17). Given the rarity of EPSCC, there are no prospective trials to guide management. Treatment of EPSCC has been largely extrapolated from the treatment of small cell carcinomas from other anatomic locations, namely small cell lung carcinoma, which favors concurrent chemotherapy with radiation therapy. A single-center retrospective study of 120 patients with predominantly non-metastatic EPSCC had comparable survival to patients with limited disease small cell lung cancer treated at the same institution (2). Another retrospective study of 5,747 patients with EPSCC from the National Cancer Database (NCDB) between 20062014 found that concurrent chemotherapy and radiation demonstrated improved overall survival to chemotherapy or radiation alone (3). These findings have led to the adoption of the treatment approach for small cell lung carcinoma to the management of EPSCC. While small cell carcinoma of the lungs has a predilection for central nervous system involvement, EPSCC has been shown to have a lower risk of CNS metastases $(2,18,19)$. Therefore, prophylactic cranial irradiation has not been widely adopted in the treatment of EPSCC.

The case we discuss represents the only anal small cell carcinoma case we are aware of with a durable response nearly 36 months after diagnosis. While objective responses to concurrent chemotherapy and radiation are commonly observed, nearly all cases relapsed within 12 months of diagnosis, usually after treatment with concurrent chemotherapy and radiation. Given the high risk of relapse, 
3152 Chuang et al. Locally advanced anal small cell carcinoma with durable complete response to multimodality therapy: case report

Table 2 Case reports of anal small cell carcinoma

\begin{tabular}{|c|c|c|c|c|}
\hline Author (year) & Clinical presentation & Treatment & Clinical outcome & Citation \\
\hline Alcindor [2008] & $\begin{array}{l}\text { 45-year-old male with HIV } \\
\text { found to have anal small } \\
\text { cell carcinoma with liver } \\
\text { metastases }\end{array}$ & $\begin{array}{l}\text { Chemoradiation with cisplatin and } \\
\text { etoposide }\end{array}$ & $\begin{array}{l}\text { Progression of disease after initial } \\
\text { response to therapy; deceased } 6 \\
\text { months after diagnosis }\end{array}$ & (9) \\
\hline Doddi [2009] & $\begin{array}{l}60 \text {-year-old female with } \\
\text { localized anal small cell } \\
\text { carcinoma }\end{array}$ & $\begin{array}{l}\text { Chemotherapy with cisplatin and } \\
\text { etoposide followed by radiation therapy }\end{array}$ & $\begin{array}{l}\text { Clinical relapse } 12 \text { months after } \\
\text { completion of therapy; deceased } \\
18 \text { months after initial diagnosis }\end{array}$ & (10) \\
\hline Khan [2009] & $\begin{array}{l}50 \text {-year-old male with locally } \\
\text { advanced anal small cell } \\
\text { carcinoma }\end{array}$ & $\begin{array}{l}\text { Initial treatment with chemoradiation } \\
\text { with cisplatin and etoposide; surgery and } \\
\text { repeat chemoradiation with cisplatin/ } \\
\text { irinotecan for local recurrence. Repeat } \\
\text { radiation non-overlapping with initial } \\
\text { fields. Third line topotecan for bony } \\
\text { recurrence }\end{array}$ & $\begin{array}{l}\text { Complete response to chemoradiation } \\
\text { followed by local recurrence } 24 \text { months } \\
\text { after completion of initial therapy. Patient } \\
\text { achieved another } 24 \text { months of disease- } \\
\text { free after repeat chemoradiation interval } \\
\text { prior to developing bony recurrence }\end{array}$ & (11) \\
\hline Khmou [2014] & $\begin{array}{l}\text { 53-year-old male with locally } \\
\text { advanced anal small cell } \\
\text { carcinoma }\end{array}$ & Chemoradiation & Deceased 12 months after diagnosis & (14) \\
\hline Surag [2016] & $\begin{array}{l}\text { 46-year-old-male with locally } \\
\text { advanced anal small cell } \\
\text { carcinoma with involvement } \\
\text { of inguinal, mesorectal and } \\
\text { internal iliac lymph nodes }\end{array}$ & $\begin{array}{l}\text { Surgery followed by adjuvant } \\
\text { chemotherapy with cisplatin and } \\
\text { etoposide }\end{array}$ & $\begin{array}{l}\text { Disease progression while on } \\
\text { chemotherapy; deceased } 4 \text { months after } \\
\text { diagnosis }\end{array}$ & (15) \\
\hline
\end{tabular}

the addition of consolidation systemic therapy to concurrent chemoradiation in our case likely further decreased the risk of relapse in our patient and prolonged overall survival. Furthermore, in contrast to previous cases reported, we administered a protocol of cisplatin and etoposide that is more commonly seen in the treatment of non-small cell cancer, which concurrently with pelvic irradiation is feasible and well tolerated. Therefore, this novel approach to 
management should be strongly considered for treatment of this rare and aggressive disease.

In conclusion, small cell anal carcinoma is a rare and poorly understood entity with sparse data to guide management of this aggressive disease. Risk of relapse is high despite treatment with concurrent chemotherapy and radiation. An aggressive approach to management with the addition of consolidation chemotherapy to concurrent chemoradiation may offer prolonged disease-free survival and improved overall survival. Further studies will be required to delineate the risk factors for developing this disease and better define the treatment approach for this rare entity.

\section{Acknowledgments}

Funding: None.

\section{Footnote}

Reporting Checklist: The authors have completed the CARE reporting checklist. Available at https://dx.doi. org/10.21037/jgo-21-434

Conflicts of Interest: All authors have completed the ICMJE uniform disclosure form (available at https://dx.doi. org/10.21037/jgo-21-434). Dr. MF has consulted for HalioDx, Mirati, Pfizer, Taiho, and Zhuhai Yufan Biotech. He has served on Advisory Boards for Amgen, Array Biopharma, Bayer, GSK, Mirati and Seattle Genetics. He has received Honoraria or participated in Speaker Bureaus for Amgen and Guardant Health. Dr. VP is a consultant for Genentech. The other authors have no conflicts of interest to declare.

Ethical Statement: The authors are accountable for all aspects of the work in ensuring that questions related to the accuracy or integrity of any part of the work are appropriately investigated and resolved. All procedures performed in studies involving human participants were in accordance with the ethical standards of the City of Hope institutional research board research committee(s) and with the Helsinki Declaration (as revised in 2013). This study was conducted under an Institutional Review Board approved protocol (IRB14361). Because this was an outcome analysis study and the case was de-identified, the Institutional Review Board did not require an informed consent.
Open Access Statement: This is an Open Access article distributed in accordance with the Creative Commons Attribution-NonCommercial-NoDerivs 4.0 International License (CC BY-NC-ND 4.0), which permits the noncommercial replication and distribution of the article with the strict proviso that no changes or edits are made and the original work is properly cited (including links to both the formal publication through the relevant DOI and the license). See: https://creativecommons.org/licenses/by-nc-nd/4.0/.

\section{References}

1. Ryan DP, Compton CC, Mayer RJ. Carcinoma of the anal canal. N Engl J Med 2000;342:792-800.

2. Brennan SM, Gregory DL, Stillie A, et al. Should extrapulmonary small cell cancer be managed like small cell lung cancer? Cancer 2010;116:888-95.

3. Mandish SF, Gaskins JT, Yusuf MB, et al. Extrapulmonary small cell carcinoma: Prognostic factors, patterns of care, and overall survival. Eur J Surg Oncol 2020;46:1596-604.

4. Wong YN, Jack RH, Mak V, et al. The epidemiology and survival of extrapulmonary small cell carcinoma in South East England, 1970-2004. BMC Cancer 2009;9:209.

5. Brammer JE, Lulla P, Lynch GR. Retrospective review of extra-pulmonary small cell carcinoma and prognostic factors. Int J Clin Oncol 2014;19:822-8.

6. Walenkamp AM, Sonke GS, Sleijfer DT. Clinical and therapeutic aspects of extrapulmonary small cell carcinoma. Cancer Treat Rev 2009;35:228-36.

7. Nakahara H, Moriya Y, Shinkai T, et al. Small cell carcinoma of the anus in a human HIV carrier: report of a case. Surg Today 1993;23:85-8.

8. Meyer A, Bruns F, Richter K, et al. Small cell cancer of the anal canal--case report of a rare tumor. Anticancer Res 2007;27:1047-50.

9. Alcindor T, Tosikyan A, Vuong T, et al. Small-cell anal carcinoma and AIDS: case report and review of the literature. Int J Colorectal Dis 2008;23:135-6.

10. Doddi S, Singhal T, De Silva C, et al. Small cell carcinoma of the anus: a case report. Cases J 2009;2:9396.

11. Khan GN, Siddiqui M, Ben-Josef E, et al. An unusual case of small cell carcinoma of the anal canal. Am J Clin Oncol 2009;32:543-4.

12. Eberhardt JM, Brown K, Lo S, et al. Extrapulmonary small cell carcinoma of the anal canal: a case report and review of the literature. Case Rep Med 2012;2012:341432.

13. Marcus DM, Edgar MA, Hawk NN, et al. Small cell carcinoma of the anus in the setting of prior squamous 
dysplasia and carcinoma in situ. J Gastrointest Oncol 2013;4:E1-4.

14. Khmou M, Zouaidia F, Ouazzani H, et al. Small-cell carcinoma of the anal canal: Case report of a rare tumor. African Journal of Cancer 2014;6:186-8.

15. Surag, Neeralagi C, Prasath A, et al. Small Cell Carcinoma of Anal Canal - A Rare Case Report. J Clin Diagn Res 2016;10:PD14-5.

16. Cimino-Mathews A, Sharma R, Illei PB. Detection of human papillomavirus in small cell carcinomas of the anus and rectum. Am J Surg Pathol 2012;36:1087-92.

Cite this article as: Chuang $\mathrm{J}$, Wang $\mathrm{C}$, Parekh V, Fakih M. Locally advanced anal small cell carcinoma with durable complete response to chemoradiation followed by consolidation chemotherapy: case report and literature review. J Gastrointest Oncol 2021;12(6):3148-3154. doi: 10.21037/jgo-21-434
17. Boman BM, Moertel CG, O'Connell MJ, et al. Carcinoma of the anal canal. A clinical and pathologic study of 188 cases. Cancer 1984;54:114-25.

18. Cicin I, Karagol H, Uzunoglu S, et al. Extrapulmonary small-cell carcinoma compared with small-cell lung carcinoma: a retrospective single-center study. Cancer 2007;110:1068-76.

19. Soto DE, Eisbruch A. Limited-stage extrapulmonary small cell carcinoma: outcomes after modern chemotherapy and radiotherapy. Cancer J 2007;13:243-6. 